\title{
1 Stiffness evolution of natural hydraulic lime mortars at early ages
}

measured through EMM-ARM

\section{ABSTRACT:}

${ }^{1}$ Corresponding author. Email address: miguel.azenha@civil.uminho.pt (M. Azenha). s/n, 13071 Ciudad Real, Spain Sample preparation.

\section{INTRODUCTION}

B. Lourenço ${ }^{b}$, Gonzalo Ruiz ${ }^{a}$

${ }^{a}$ ETS de Ingenieros de Caminos, C. y P., Universidad de Castilla-La Mancha. Avda. Camilo José Cela,

${ }^{b}$ ISISE - Instituto para a Sustentabilidades e Inovação em Estruturas de Engenharia, Universidade do Minho, Escola de Engenharia, Campus de Azurém, 4800 Guimarães, Portugal

This paper focuses on the mechanical characterization of the early age behavior of three NHL mortars with different water/lime ratios. A vibration-based technique with continuous data recording (Elastic Modulus Measurement through Ambient Response Method - EMM-ARM) was used to measure stiffness of the different mortars that were found to range between 2.5 and $4.1 \mathrm{GPa}$ on day 7 . Other physical and mechanical properties such as strength and density were measured as a function of sample preparation protocols -vibrated, compacted, sealed and unsealed. After 7 days, sealed specimens led to $50 \%$ lower compressive strength and $25 \%$ lower flexural strength compared to unsealed specimens.

KEYWORDS: Natural Hydraulic Lime (NHL) mortars, Elastic Modulus Measurement through Ambient Response Method (EMM-ARM), Stiffness evolution, Ultrasonic pulse velocity test (UPV),

Natural hydraulic lime mortars, henceforward referred to as NHL, are widely used for restoration of historic buildings and structures (particularly in the case of masonry) due to their good compatibility with the substrate material and eco-efficiency (hydraulic lime consumes low amount of energy during its 
25 production process in comparison with cementitious materials, and it naturally absorbs environmental

26 carbon dioxide after being applied in construction) [1]. From the mechanical point of view, NHL mortars

27 are also very suitable for restoration works because they are able to accommodate minor differential

28 movement of masonry over time without cracking [2]. However, despite awareness of the importance of

29 the early age conditions of application, curing and stiffness build-up in the actual behavior of NHL

30 mortars, little research is found about the behavior of these mortars at early ages. For instance, Lanas

31 et al. [3] performed flexural and compression tests and thermogravimetric analyses (TGA) on mortars

32 with NHL type 5 at 3 and 7 days. Arandigoyen and Alvarez [4] tested aerial lime mortars with cement in

33 bending and compression after 3 and 7 days. However, the literature review conducted in the scope of this

34 paper did not encounter any study/report focused on the stiffness evolution of NHL mortars at early ages,

35 particularly including the first $48 \mathrm{~h}$ of hardening. This is of crucial importance because the behavior of

36 NHL mortars at early ages has a direct influence on the supporting capability and ability to accommodate

37 movements of masonry during construction or repairing operations. This behavior is especially relevant

38 for interventions in historic structures, where an appropriate large deformation before failure of the new

39 additions helps to avoid brittle breakage when restrained by preexistent elements.

40 For these reasons, the objective of this research is to study the behavior of three NHL mortars at early

41 ages (same binder, with three distinct water/binder ratios). An exhaustive mechanical and physical 42 characterization of these mortars was performed, including the measurement of the elastic modulus 43 through two methods: Elastic Modulus Measurement through Ambient Response Method (EMM-ARM) 44 [5], and Cyclic Compression test (CC) on cylinders. Furthermore, the following tests and property 45 assessments have also been deployed: penetration resistance test to study the initial setting time of the 46 mortars; density and normalized flexural and compressive strength tests on prisms at days 2, 4 and 7; 47 open porosity and, finally, thermogravimetric analysis on the corresponding lime paste to study the 48 evolution of portlandite $\left(\mathrm{Ca}(\mathrm{OH})_{2}\right)$ content that results from the hydration of the NHL compounds, 49 (mainly $\left.\mathrm{C}_{2} \mathrm{~S}\right)[3]$.

50 One of the most striking novelties of this research lies on the pioneering application of the 51 EMM-ARM technique to NHL mortars. This test allows automatic and continuous evaluation of the 52 Elastic Modulus immediately after casting without demolding the specimen. EMM-ARM is based on the 53 continuous evaluation of the resonance frequency of the tested specimen (simply supported composite 
54 beam), which can in turn allow direct evaluation of the tested material through application of the dynamic

55 equation of motion of the system [5-9]. For further comprehension of the early age behavior of NHL

56 mortars, some relations were established among the results of the several conducted tests. In such way,

57 EMM-ARM was compared with the results of $\mathrm{CC}$ on one reference mortar and penetration resistance

58 tests on the three NHL mortars. Due to the nature of the EMM-ARM testing adopted, as well as its

59 principles of operation, the test specimen is relatively slender (50.5 cm long cylinder), and the specimen

60 needs to be kept within the mold during testing, in order to keep the same mechanical boundary

61 conditions and avoid mass losses. These experimental requirements of EMM-ARM led to the need for

62 vibration in the preparation of EMM-ARM samples (due to the long and thin mold), and the specimens

63 were constantly sealed. These vibrated/sealed conditions do not match the fabrication/curing conditions

64 required in the standards for NHL [10], which include compaction with 25 strokes of the tamper and

65 unsealed curing conditions. Also, keeping the specimens sealed hinders the process of carbonation, which

66 plays a role in the hardening of NHL mortars as well. For that reason, EMM-ARM, as performed herein,

67 was limited to the maximum age of 7 days, during which the effects of carbonation would presumably

68 still have been minor as in the case of unsealed curing. Anyhow, it was important to ascertain the impact

69 of fabrication (compaction/vibration) and curing (sealed/unsealed) conditions in the studied NHL mortars

70 so as to allow further conclusions to be drawn from the obtained results. Density, flexural and

71 compressive strength tests were carried out on samples with different preparation and curing methods: the

72 standard one (compacted with 25 strokes of the tamper and unsealed), the one followed in the preparation

73 of EMM-ARM specimens (vibrated and sealed) and an additional one (compacted and sealed). In such

74 way, it was possible to relate the results of such tests implying stiffness and strength measurements.

75 Furthermore, some relations were also established among the results of density, ultrasonic pulse velocity

76 (UPV) and open porosity of the three mortars to better understand the interplay of these properties on the

77 behavior of NHL mortars at early ages. Finally, the evolution of free portlandite content of one reference

78 NHL paste was related to the compressive strength of the corresponding mortar through the performance

79 of thermogravimetric analysis.

80 The rest of the paper is organized as follows. After this introduction, Section 2 describes the materials

81 and experimental procedure, whereas Section 3 pertains to the discussion of attained results, with

82 conclusions being drawn in Section 4. 


\section{$84 \quad 2.1$ Raw materials}

The three mortars were prepared with a commercial natural hydraulic lime of class NHL 3.5,

86 according to EN 459-1 [11] that was supplied by "Socli, Italcementi Group" (France). It had a density of

$872.58 \mathrm{~g} / \mathrm{cm}^{3}$ and an apparent density of $0.85 \mathrm{~g} / \mathrm{cm}^{3}$.Chemical and mineralogical analyses of the natural

88 hydraulic lime, NHL 3.5, are provided in Table 1 and Fig. 1. They were performed by X-ray fluorescence

89 (XRF) and X-ray diffraction (XRD) analyses by using a Philips (PANALYTICAL) Magis Pro X-ray

90 fluorescence spectrometer, and a Philips (PANALYTICAL) X'Pert MPD diffractometer, respectively.

91

92

Table 1.Chemical and mineralogical compositions of the NHL 3.5.

\begin{tabular}{|c|c|}
\hline \multicolumn{2}{|c|}{ Chemical composition (\%) } \\
\hline $\mathrm{Na}_{2} \mathrm{O}$ & 0.125 \\
\hline $\mathrm{MgO}$ & 3.078 \\
\hline $\mathrm{Al}_{2} \mathrm{O}_{3}$ & 2.051 \\
\hline $\mathrm{SiO}_{2}$ & 13.606 \\
\hline $\mathrm{P}_{2} \mathrm{O}_{5}$ & 0.044 \\
\hline $\mathrm{SO}_{3}$ & 0.990 \\
\hline $\mathrm{K}_{2} \mathrm{O}$ & 0.456 \\
\hline $\mathrm{CaO}$ & 59.949 \\
\hline $\mathrm{TiO}_{2}$ & 0.132 \\
\hline $\mathrm{MnO}$ & 0.014 \\
\hline $\mathrm{Fe}_{2} \mathrm{O}_{3}$ & 0.994 \\
\hline $\mathrm{NiO}$ & 0.014 \\
\hline $\mathrm{CuO}$ & 0.007 \\
\hline $\mathrm{ZnO}$ & 0.004 \\
\hline $\mathrm{SeO}_{2}$ & 0.002 \\
\hline $\mathrm{Rb}_{2} \mathrm{O}$ & 0.003 \\
\hline $\mathrm{SrO}$ & 0.169 \\
\hline $\mathrm{CO}_{2}$ & 18.365 \\
\hline \multicolumn{2}{|c|}{ Mineral phases (\%) } \\
\hline Portlandite, $\mathrm{Ca}(\mathrm{OH})_{2}$ & $40-45$ \\
\hline Calcite, $\mathrm{CaCO}_{3}$ & $40-45$ \\
\hline Calcium silicates & $10-15$ \\
\hline
\end{tabular}

93 


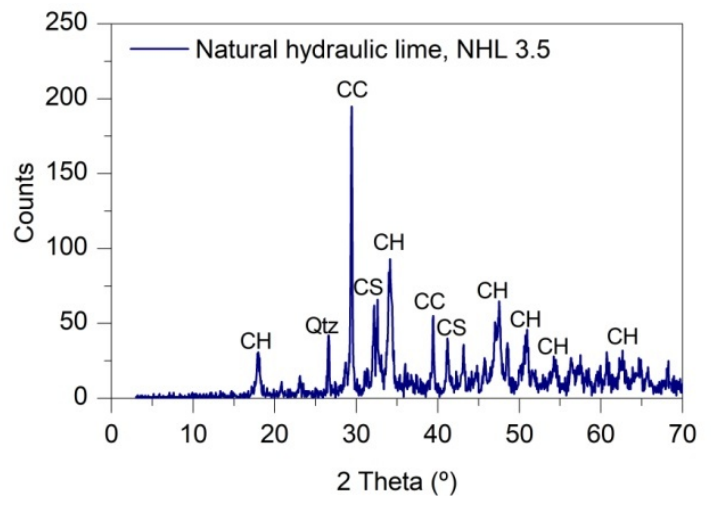

Figure 1: X-ray diffraction pattern of the NHL 3.5. $\mathrm{CH}=$ portlandite, $\mathrm{CC}=$ calcite, $\mathrm{CS}=$ calcium silicates, Qtz = quartz.

Also, the laser particle size distribution curve of the NHL 3.5 was obtained by means of a PSD Mastersizer 3000 from Malvern Instruments, see Fig. 2.

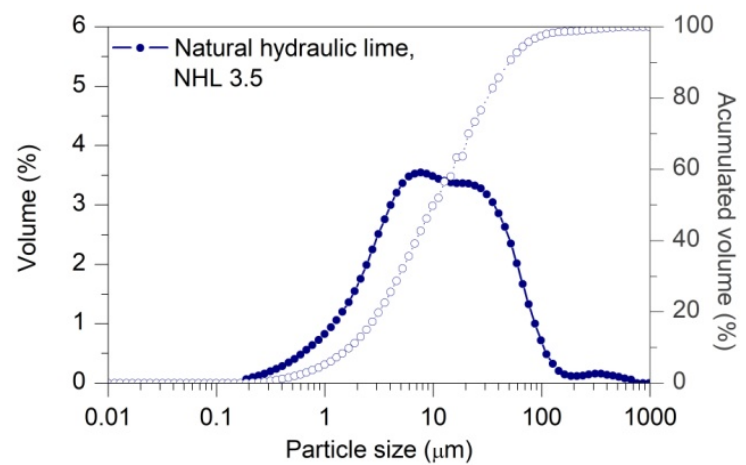

Figure 2: Results of laser particle size distribution for NHL 3.5.

The sand used was commercial crushed limestone of maximum grain size of $4 \mathrm{~mm}$ and had a particle size distribution curve- presented in Figure 3, determined according to EN 1015-1 [12]. It had an apparent particle density of $2.68 \mathrm{~g} / \mathrm{cm}^{3}$ according to EN 1097-6 [13] and an apparent density of $1.82 \mathrm{~g} / \mathrm{cm}^{3}$ according to EN 1097-3 [14].

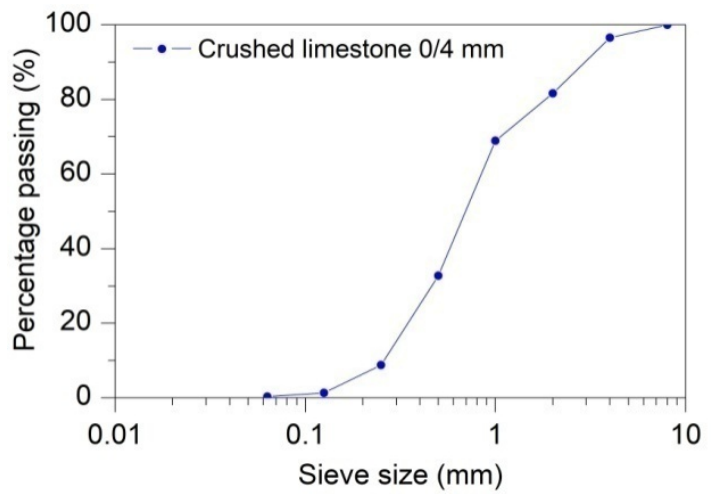

Figure 3: Particle size distribution curve of the aggregate used. 


\subsection{Mortar composition and preparation}

Three mortar compositions were prepared with different water/lime ratios: $0.8,0.9$ and 1.1 by volume,

Table 2: Mortar compositions for each NHL mortar

\begin{tabular}{ccccccc}
\hline Mortar & $\begin{array}{c}\text { Lime/aggregate } \\
\text { ratio by } \\
\text { volume }\end{array}$ & NHL $(\mathrm{g})$ & $\begin{array}{c}\text { Aggregate } \\
(\mathrm{g})\end{array}$ & $\begin{array}{c}\text { Water } \\
\left(\mathrm{cm}^{3}\right)\end{array}$ & $\begin{array}{c}\text { Water/lime } \\
\text { ratio by } \\
\text { volume }\end{array}$ & $\begin{array}{c}\text { Water/lime } \\
\text { ratio by } \\
\text { weight }\end{array}$ \\
\hline M0.8 & $1: 3$ & 525.2 & 3367.3 & 494.3 & 0.8 & 0.94 \\
M0.9 & $1: 3$ & 514.5 & 3298.6 & 544.7 & 0.9 & 1.06 \\
M1.1 & $1: 3$ & 494.3 & 3169.2 & 639.7 & 1.1 & 1.29 \\
\hline
\end{tabular}

Different sizes of specimens, compacting methods and curing conditions were used depending on the test to be applied (Table 3). The reason for the distinct fabrication conditions employed has been given in the introduction of this paper. Standard mortars were compacted with 25 strokes of the tamper and cured unsealed inside a climatic chamber at relative humidity $(\mathrm{RH}) 95 \%$ and $20^{\circ} \mathrm{C}$. This humidity is recommended by EN 1015-11 [10] and is reported to favor the hydration of NHL mortars [18-20]). These mortars were tested to measure UPV, flexural and compressive strengths and open porosity. In the table, the column "Type of mortar" includes the nomenclature M0.8, M0.9 and M1.1, with an additional suffix that clarifies the fabrication/curing conditions: suffix "S" for the standard situation that has just been described namely - compacted and unsealed (air cured); suffix "V" for vibrated (with a vibration table) and sealed (inside the PVC tubes of the EMM-ARM samples or covered with two plastic bags in the case 
156 of the rest of the samples); suffix " $\mathrm{C}$ " for compacted (with 25 strokes of the tamper) and sealed

157 (following the same aforementioned procedure). All the mortars remained in climatic chambers with

158 corresponding curing conditions as indicated in Table 3. The days at which the different specimens were

159 removed from their corresponding molds are also referred to in Table 3. Furthermore, a lime paste

160 specimen has been prepared for TGA testing, with water to lime ratio of 0.9: P0.9.

Table 3: Sizes of specimens, compacting methods and curing conditions of the NHL mortars.

\begin{tabular}{|c|c|c|c|c|c|}
\hline Tests & $\begin{array}{l}\text { Specimen shape } \\
\text { and dimensions } \\
(\mathrm{mm})\end{array}$ & Type of mortar & $\begin{array}{l}\text { Curing } \\
\text { conditions }\end{array}$ & $\begin{array}{l}\text { Compacting } \\
\text { method and } \\
\text { sealing } \\
\text { conditions }\end{array}$ & $\begin{array}{l}\text { Time of } \\
\text { demolding }\end{array}$ \\
\hline EMM-ARM & $\begin{array}{l}\text { Cylinder } \\
\phi 44 \times 505\end{array}$ & $\begin{array}{l}\mathrm{M} 0.8 \mathrm{~V}, \mathrm{M} 0.9 \mathrm{~V}, \\
\mathrm{M} 1.1 \mathrm{~V}\end{array}$ & $\begin{array}{l}20^{\circ} \mathrm{C} \\
\text { - sealed }\end{array}$ & $\begin{array}{l}\text { (V) Vibrated } \\
\text { and sealed }\end{array}$ & $\begin{array}{l}\text { No } \\
\text { demolding }\end{array}$ \\
\hline $\mathrm{CC}$ & $\begin{array}{l}\text { Cylinder } \\
\phi 75 \times 150\end{array}$ & M0.9S & $\begin{array}{l}20^{\circ} \mathrm{C}- \\
\mathrm{RH} 95 \%\end{array}$ & (S) Standard & At day 2 \\
\hline $\mathrm{CC}$ & $\begin{array}{l}\text { Cylinder } \\
\phi 75 \times 150\end{array}$ & M0.9V & $\begin{array}{l}20^{\circ} \mathrm{C}- \\
\mathrm{RH} 95 \%\end{array}$ & $\begin{array}{l}\text { (V) Vibrated } \\
\text { and sealed }\end{array}$ & $\begin{array}{l}\text { Before } \\
\text { testing }\end{array}$ \\
\hline $\begin{array}{l}\text { UPV (discrete } \\
\text { measurements) - } \\
\text { flexural and } \\
\text { compression }\end{array}$ & Prisms $40 \times 40 \times 160$ & $\begin{array}{l}\text { M0.8S, M0.9S, } \\
\text { M1.1S }\end{array}$ & $\begin{array}{l}20^{\circ} \mathrm{C}- \\
\mathrm{RH} 95 \%\end{array}$ & (S) Standard & At day 2 \\
\hline $\begin{array}{l}\text { UPV (discrete } \\
\text { measurements) - } \\
\text { flexural and } \\
\text { compression }\end{array}$ & Prisms $40 \times 40 \times 160$ & $\begin{array}{l}\mathrm{M} 0.8 \mathrm{~V}, \mathrm{M} 0.9 \mathrm{~V} \\
\mathrm{M} 1.1 \mathrm{~V}\end{array}$ & $\begin{array}{l}20^{\circ} \mathrm{C}- \\
\mathrm{RH} 95 \%\end{array}$ & $\begin{array}{l}\text { (V) Vibrated } \\
\text { and sealed }\end{array}$ & At day 2 \\
\hline $\begin{array}{l}\text { Flexural and } \\
\text { compression }\end{array}$ & Prisms $40 \times 40 \times 160$ & $\begin{array}{l}\text { M0.8C, M0.9C, } \\
\text { M1.1C }\end{array}$ & $\begin{array}{l}20^{\circ} \mathrm{C}- \\
\mathrm{RH} 95 \%\end{array}$ & $\begin{array}{l}\text { (C) Compacted } \\
\text { and sealed }\end{array}$ & At day 2 \\
\hline Open porosity & Prisms $40 \times 40 \times 160$ & $\begin{array}{l}\text { M0.8S, M0.9S, } \\
\text { M1.1S }\end{array}$ & $\begin{array}{l}20^{\circ} \mathrm{C}- \\
\mathrm{RH} 95 \%\end{array}$ & (S) Standard & At day 2 \\
\hline Open porosity & Prisms $40 \times 40 \times 160$ & $\begin{array}{l}\mathrm{M} 0.8 \mathrm{~V}, \mathrm{M} 0.9 \mathrm{~V}, \\
\mathrm{M} 1.1 \mathrm{~V}\end{array}$ & $\begin{array}{l}20^{\circ} \mathrm{C}- \\
\mathrm{RH} 95 \%\end{array}$ & $\begin{array}{l}\text { (V) Vibrated } \\
\text { and sealed }\end{array}$ & At day 2 \\
\hline TGA & $\begin{array}{l}\text { N/A (sample of } \\
\text { less than } 20 \mathrm{mg} \text { ) }\end{array}$ & P0.9 & $\begin{array}{l}20^{\circ} \mathrm{C}- \\
\mathrm{RH} 95 \%\end{array}$ & Sealed & $\begin{array}{l}\text { Before } \\
\text { testing }\end{array}$ \\
\hline
\end{tabular}

\subsection{Test procedures}

\subsubsection{Elastic Modulus Measurement through Ambient Response Method (EMM-ARM)}

The EMM-ARM is a methodology proposed by Azenha et al. [5] for cement-based materials. It has been widely validated for cement pastes [7, 21-23], cement mortars [7], concrete [5, 24] and recently for aerial lime-cement mortars [25]. In this paper, it was applied for the first time to the study of NHL mortars. This method allows the automatic and continuous evaluation of the elastic modulus immediately after casting and it has two fundamental differences compared to conventional resonant frequency methods (e.g. impact-resonance methods): (i) the resonant frequencies are much lower, well below $1 \mathrm{kHz}$ 
171 (thus more similar to quasi-static testing); (ii) the specimen is not demolded during testing [23]. The

172 methodology is based on continuous modal identification of the first flexural resonant frequency of a

173 composite beam that is placed horizontally, simply supported at both ends in the case of concrete and

174 some mortars (in contrast with the cantilever beam configuration used for pastes). A typical setup adopted

175 during the present experimental program is shown in Fig. 4. At mid-span of the beam, vertical

176 accelerations resulting from forced vibration with a non-contact magnetic actuator are measured. With

177 this, it is possible to perform modal identification and evaluate the first flexural resonance frequency of

178 the beam. This resonant frequency of the beam is related to the increasing elastic modulus of the tested

179 material by applying the dynamic equation of motion of the system (all variables known except for elastic

180 modulus, which can be directly computed). In this way it is possible to obtain a real-time curve of elastic

181 modulus against time [26].

182

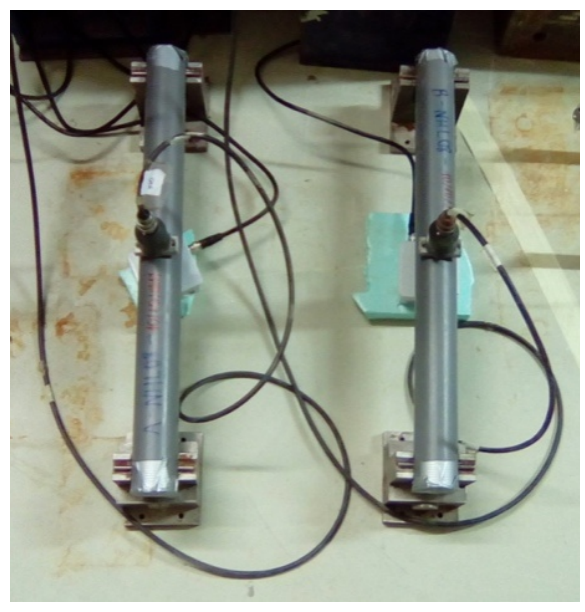

Figure 4: EMM-ARM setup.

The specimens used in this study were prepared with a PVC tube with inner/outer diameter of $44 \mathrm{~mm} / 50 \mathrm{~mm}, 550 \mathrm{~mm}$ length and with a span of $500 \mathrm{~mm}$ between supports. Two specimens per mortar mix were cast and tested (Fig. 4). The mortar was always vibrated as it was introduced in the tubes. After casting, the acceleration measurements could start within a period of less than 30 minutes since the mixing of lime and water. The samples remained sealed in the mold during the whole test for seven days.

\subsubsection{Cyclic Compression tests (CC)}

Cyclic Compression (CC) tests were made on cylindrical specimens to measure the elastic modulus at ages of 2, 4 and 7 days on the reference mortars, M0.9S and M0.9V, and compared with the results 
obtained with EMM-ARM. The specimens had a diameter/height of $75 \mathrm{~mm} / 150 \mathrm{~mm}$. A hydraulic actuator with $25 \mathrm{kN}$ capacity was used for load application, and three Linear Variable Differential Transducers (LVDTs), supported by 2 centered steel rings were attached to the specimens at $120^{\circ}$ intervals, with a reference measuring span of $50 \mathrm{~mm}$ [23]. The test protocol was similar to the one followed in references $[18,27]$ : each test involved 5 loading/unloading cycles up to $30 \%$ of the maximum load obtained in a compression test performed on one extra cylinder (at the same age of testing). The displacement rate of the cycle to obtain the elastic modulus was $0.7 \mathrm{~mm} / \mathrm{min}$ (in displacement control to better perform the test at such early ages). After each test, the specimens were broken in compression at $10 \mathrm{~N} / \mathrm{s}$ to evaluate the compressive strength.

\subsubsection{Penetration resistance tests}

Penetration tests were applied on the three mortar compositions, M0.8V, M0.9V and M1.1V, according to standard ASTM C-403 [28] for concrete as a reference. A penetrometer by Controls, model 54-C0145, was used. The purpose of this test was to obtain the initial setting time of the mixes and compare it with the early singularities of continuous monitoring provided by EMM-ARM. Cubic molds of $150 \mathrm{~mm}$ edge length were used. The time of initial setting is measured as the moment when the penetration resistance, measured by the shank of a needle, equals $3.5 \mathrm{MPa}$.

\subsubsection{Ultrasound Pulse Velocity tests (UPV)}

The UPV test is a method that consists in generating a pulse on one side of the sample, which is transmitted through the material and received on the opposite side of the sample. The time delay between the generated and received signals is recorded to obtain the wave travel time through the material. The velocity of the compressional $(\mathrm{P})$ wave, $V_{p}$, can be related to the elastic properties of the medium (the dynamic Poisson's ratio, $v_{d y n}$, and the dynamic elastic modulus, $E_{d y n}$ ) and the density, $\rho$, through the following equation, which is applicable for homogeneous and isotropic media [23, 29].

$$
V_{P}=\sqrt{\frac{\left(1-v_{d y n}\right) E_{d y n}}{\left(1+v_{d y n}\right)\left(1-2 v_{d y n}\right) \rho}}
$$

UPV was measured in some specimens at discrete times in the transverse direction (Fig. 5), particularly in the specimens used for flexural and compressive strength tests. UPV velocity was measured just before the actual mechanical tests. The ultrasound probes had $25 \mathrm{~mm}$ diameter and 
operating frequency of $150 \mathrm{kHz}$. Probe of this diameter was considered adequate, as it was larger than the largest expected heterogeneity of the mortar. Spacing between the probes was set as $40 \mathrm{~mm}$, longer than two wavelengths at the selected operating frequency [23].

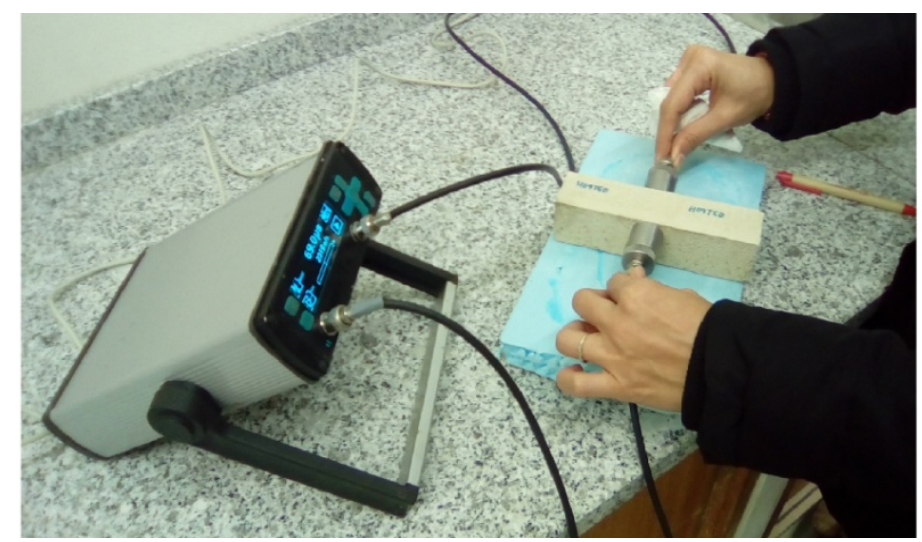

Figure 5: UPV set-up. Discrete measurement in the lateral direction.

\subsubsection{Flexural and compressive strength tests}

Flexural and compressive strengths were measured at 2, 4 and 7 days. The standard EN 1015-11 [10] was observed. Flexural strength was measured by three-point bending on three $40 \mathrm{~mm} \times 40 \mathrm{~mm} \times$ $160 \mathrm{~mm}$ specimens applying a displacement rate of $0.2 \mathrm{~mm} / \mathrm{min}$. Compressive strength tests that were conducted on six of the resulting half-prisms from the flexural strength tests, also employed displacement control at $0.7 \mathrm{~mm} / \mathrm{min}$. These were the same displacement rates as the ones adopted in [19], instead of the ones set by the standard, to better control the tests at such early ages.

\subsubsection{Open porosity}

Open porosity was measured on the three mortar mixes, particularly M0.8S, M0.9S and M1.1S and $\mathrm{M} 0.8 \mathrm{~V}, \mathrm{M} 0.9 \mathrm{~V}$ and $\mathrm{M} 1.1 \mathrm{~V}$, at day 7 , according to UNE 83980 [30] for concrete as a reference, which is determined according to water saturation. In this test, dry weight of the samples $\left(m_{l}\right)$, weight after water saturation in a vacuum pump $\left(m_{3}\right)$ and apparent weight $\left(m_{4}\right)$ with a hydrostatic balance were measured. The open porosity, $O P$, in percentage, was then obtained by equation 2 .

$$
O P=\frac{m_{3}-m_{1}}{m_{3}-m_{4}} 100
$$




\subsubsection{Thermogravimetric analyses (TGA)}

In thermogravimetric analysis (TGA), a material sample is submitted to a defined rate of temperature change until a maximum value is reached [31-33]. The mass of the sample is monitored through the temperature range, and a resulting graph can be plotted with weight $v s$. temperature - TGA curve [31-34].

In this study, thermogravimetric analyses were performed on the lime paste of the corresponding reference mortar, P0.9 at day $0,2,4$ and 7 to study the evolution of hydration by means of free portlandite, $\mathrm{Ca}(\mathrm{OH})_{2}$, content (Eq. (3)).

$$
2\left(2 \mathrm{CaO} \cdot \mathrm{SiO}_{2}\right)+4 \mathrm{H}_{2} \mathrm{O} \rightarrow 3 \mathrm{CaO} \cdot 2 \mathrm{SiO}_{2} \cdot 3 \mathrm{H}_{2} \mathrm{O}+\mathrm{Ca}(\mathrm{OH})_{2}
$$

For this purpose, samples remained sealed until the moment of testing. Before testing, the technique of hydration stoppage with isopropanol according to [35] was applied. Then a sample of less than $20 \mathrm{mg}$ was placed in an aluminum crucible. During the test, a heating rate of $10{ }^{\circ} \mathrm{C} / \mathrm{min}$ from ambient temperature up to $1000^{\circ} \mathrm{C}$ was applied so as to allow direct measurement of hydroxide and carbonate compounds at hydroxylation and decarboxylation ranges, respectively [33, 36]. According to [33, 37], dehydroxylation, which is the process of decomposition of calcium hydroxide $\left(\mathrm{Ca}(\mathrm{OH})_{2}\right)$, typically occurs in the range $300-550^{\circ} \mathrm{C}$, meanwhile the decomposition of calcium carbonate $\left(\mathrm{CaCO}_{3}\right)$, termed as decarboxylation, occurs in the range $650-950^{\circ} \mathrm{C}$.

Once the test is finished, the quantity of calcium hydroxide that is decomposed can be obtained through Eq.(4-5) [35]:

$$
\mathrm{M}_{\mathrm{P}, \mathrm{m}}=\mathrm{WL}_{\mathrm{P}} \frac{m_{P}}{m_{w}}
$$

$$
\text { Per 100g paste: } \mathrm{M}_{\mathrm{P}, \mathrm{n}}=\frac{\mathrm{M}_{\mathrm{P}, \mathrm{m}}}{\mathrm{W}_{600}(1+w / b)}
$$

where $\mathrm{M}_{\mathrm{P}, \mathrm{m}}$ is the free portlandite measured, $\mathrm{WL}_{\mathrm{P}}$ is the weight loss of the portlandite in the sample, $m_{P}$ and $m_{w}$ are the molecular masses of portlandite $\left(m_{P}=74 \mathrm{~g} / \mathrm{mol}\right)$ and water $\left(m_{w}=18 \mathrm{~g} / \mathrm{mol}\right)$, respectively, $\mathrm{M}_{\mathrm{P}, \mathrm{n}}$ is the normalized free portlandite measured in the paste, $W_{600}$ is the weight of the sample at $600^{\circ} \mathrm{C}$ and $w / b$ the water/lime ratio. 


\section{EXPERIMENTAL RESULTS AND ANALYSIS}

267

\subsection{Comparison between monitoring methods}

First of all, the results of EMM-ARM are shown for the three mortars, M0.8V, M0.9V and M1.1V (Fig. 6). For the reference mortar, M0.9, they were compared to the ones obtained through CC. Results from all three mortars were compared with the initial setting time measured through penetration resistance test.

\subsubsection{EMM-ARM}

EMM-ARM curves obtained for the three mortars tested, M0.8V, M0.9V and M1.1V, and comparison with $\mathrm{CC}$ for the reference mortars, M0.9V and M0.9S, are shown in Fig. 6. It is worth mentioning that a wide range of elastic modulus was obtained throughout the curing process of the NHL mortars, ranging from $0 \mathrm{GPa}$ to $\sim 4 \mathrm{GPa}$ within the testing period. Furthermore, all elastic modulus evolution curves seem to be plausible, showing a short initial dormant period (with elastic modulus close to $0 \mathrm{GPa}$ ), after which elastic modulus evolved significantly for all tested mortars. Then, after around one day, the slope of elastic modulus evolution curves decreased with time within the testing period. From the zoom of graph in Fig. 6, it can be seen that mortar M0.8V (specimen 1) presented some initial stiffness in the early curing hours in comparison to mortars M0.9V and M1.1V. Such initial stiffness is likely to be due to the low viscosity of the mortar stemming from its low water/lime ratio and low value of consistency $(120 \mathrm{~mm})$. Mortars M0.9V and M1.1V, with higher water/lime ratios, did not present such initial stiffness as they were more fluid.

Two samples per mortar mix were tested as shown in Fig. 6. It is possible to verify the good coherence of the two curves obtained for each mortar, demonstrating adequate repeatability of EMMARM. Mortar M0.8V presented especially good repeatability as its elastic modulus curves differed less than $0.17 \%$ at day 7 . Furthermore, it is also possible to observe that the reduction of the water/lime ratio increases early hydration rates and leads to higher values of elastic modulus. For example, at day 7, the values of $\sim 4 \mathrm{GPa}, \sim 3 \mathrm{GPa}$ and $\sim 2 \mathrm{GPa}$ were obtained respectively, for M0.8V, M0.9V and M1.1V. 


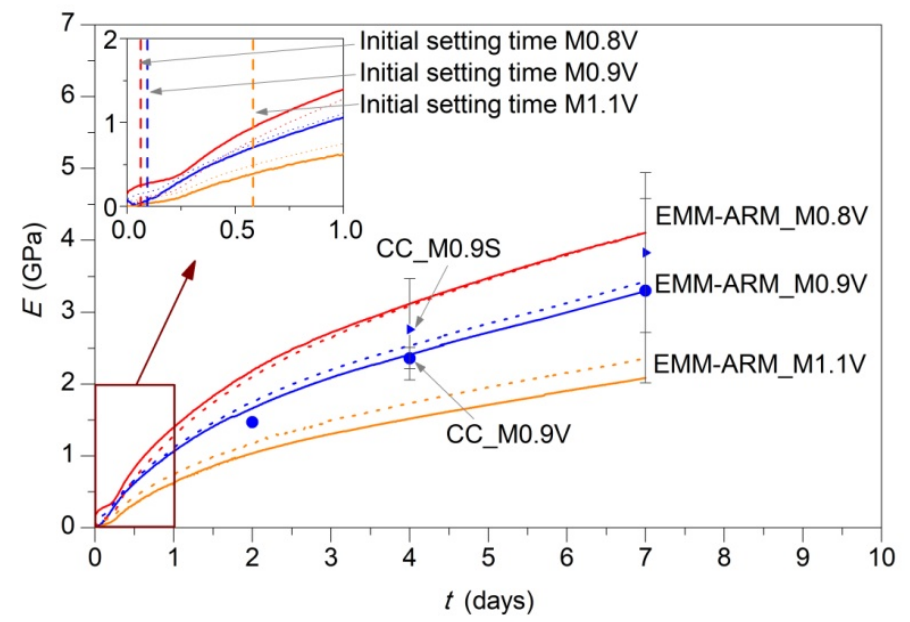

292 Figure 6: Results of EMM-ARM of the three mortars tested, comparison with CC for the reference mortar and initial setting time by means of penetration resistance test.

Table 4: Comparison of EMM-ARM and CC tests for the NHL mortars and corresponding initial setting times.

\begin{tabular}{|c|c|c|c|c|c|c|c|c|}
\hline \multirow[t]{2}{*}{$\begin{array}{l}\text { Mortar } \\
\text { type }\end{array}$} & \multirow[t]{2}{*}{$\begin{array}{l}\text { Curing } \\
\text { days }\end{array}$} & \multirow{2}{*}{$\begin{array}{c}\text { Elastic } \\
\text { modulus } \\
\text { from CC } \\
(\mathrm{GPa}) \\
\mathrm{M} 0.9\end{array}$} & \multicolumn{3}{|c|}{$\begin{array}{l}\text { Elastic modulus from } \\
\text { EMM-ARM (GPa) }\end{array}$} & \multicolumn{3}{|c|}{ Initial setting time $(\mathrm{h})$} \\
\hline & & & M0.8 & M0.9 & M1.1 & M0.8 & M0.9 & M1.1 \\
\hline \multirow{3}{*}{$\mathrm{S}$} & 2 & $1.5(-)$ & & & & & & \\
\hline & 4 & $2.8(0.7)$ & & & & & & \\
\hline & 7 & $3.8(1.1)$ & & & & & & \\
\hline \multirow{7}{*}{$\mathrm{V}$} & & & & & & 1.50 & 2.25 & 14.00 \\
\hline & \multirow{2}{*}{2} & \multirow{2}{*}{$1.5(-)$} & 2.2 & 1.7 & 1.0 & & & \\
\hline & & & 2.1 & 1.8 & 1.2 & & & \\
\hline & \multirow{2}{*}{4} & \multirow{2}{*}{$2.4(0.2)$} & 3.1 & 2.4 & 1.5 & & & \\
\hline & & & 3.1 & 2.5 & 1.7 & & & \\
\hline & \multirow{2}{*}{7} & \multirow{2}{*}{$3.3(1.3)$} & 4.1 & 3.3 & 2.1 & & & \\
\hline & & & 4.1 & 3.4 & 2.4 & & & \\
\hline
\end{tabular}

297 The comparison between the results of elastic modulus obtained by EMM-ARM and by CC for the 298 reference mortar M0.9V is also shown in Fig. 6 and Table 4 (where the notation S refers to standard 299 conditions [10] i.e. compacted and unsealed, the notation V refers to vibrated and sealed specimens (see 300 Section 2.2) and the two values shown for EMM-ARM correspond to each sample). Additionally, results 301 of CC tests of mortar M0.9S are included. It can be observed that the values obtained from EMM-ARM 302 are similar to those obtained from CC tests in terms of magnitude and shape of the curve for the reference 303 mortar vibrated and sealed, M0.9V. Results of both tests in the case of M0.9V differ by only $1.5 \%$ at day 
305 mortar, M0.9S, stiffness is higher from day 2, when the specimens were demolded, reaching a difference

306 of $14 \%$ at day 7 . However, attention is paid to the standard deviation of CC measurements (error bar in

307 Fig. 6 and values in parenthesis in Table 4), it can be observed that they are very high, especially at early

308 ages when they can reach up to $40 \%$ (at day 2 only one specimen per mortar type was measured), in

309 comparison to later testing when they normally reach $20 \%[18,27]$. Therefore, in spite of the fact of

310 M0.9S seeming to be above M0.9V in a systematic manner, this might not be a meaningful difference as

311 both measurements are within the margin of error. A possible reason for this relatively small difference

312 (14\% at day 7) can be due to carbonation reaction with $\mathrm{CO}_{2}$ from the ambient exposure that is allowed to

313 happen in M0.9S as opposed to the sealed condition of M0.9V, which would not allow carbonation.

314 However, previous works $[3,38]$ have reported that carbonation does not play a significant role until later

315 curing ages (e.g. 14 days onwards) and the main hardening mechanism in the early ages is actually

316 hydration. Further research, therefore, is needed to study the cause of this difference. All things

317 considered, it is therefore inferred that EMM-ARM can be used for very early age testing (e.g. before 2-3

318 days) for assessment of early kinetics. If longer periods of testing are intended, during which carbonation

319 is expected to play a role, then the current set up of EMM-ARM would require adaptations that involve

320 actual demolding of the specimen. This was not an objective of the present research and was thus not 321 pursued further.

322 Moreover, initial setting times of the three mortars are shown in Fig. 6 (vertical dashed lines in the 323 zoom).

324 In view of the available data, a relation between elastic-modulus as obtained by EMM-ARM and the 325 setting time, as obtained by the penetration test was sought. For the reference mortar M0.9V, the initial 326 setting happens at 2.25 hours after casting and the corresponding elastic modulus is $0.10 \mathrm{GPa}$. For the mortar M0.8V, the initial setting time is at 1.50 hours after casting (Table 4 ) and at that moment elastic-

328 modulus is around $0.46 \mathrm{GPa}$ measured from the EMM-ARM curve. For mortar M1.1V, the initial setting 329 time is recorded as 14.00 hours and the corresponding elastic modulus is $0.39 \mathrm{GPa}$. From previous 330 studies, elastic modulus obtained for cement-based materials (pastes) at the moment of setting was found 331 to range between 0.10 and $0.18 \mathrm{GPa}$ [39]. This seems to be coherent with the value obtained for the 332 reference mix $\mathrm{M} 0.9 \mathrm{~V}-0.10 \mathrm{GPa}$. However, the values of $0.46 \mathrm{GPa}$ and $0.39 \mathrm{GPa}$ are relatively more 
dispersed, and the explanation proposed is as follows. The mortar M0.8V appears to have an inherent initial stiffness at time zero, possibly due to the its relatively low water binder ratio, which increases the expected stiffness at the setting time measured. In the case of the mortar M1.1V, it is so fluid $(240 \mathrm{~mm})$ that the setting time is delayed quite a bit in addition to which it is also relatively weak. Therefore, in the time interval of 0-14 hours, the mortar had to gain some amount of stiffness before it could offer adequate resistance to penetration. More investigation is needed in order to better understand the range of elasticmoduli that should be expected from NHL mortars at the instant of setting.

\subsection{Influence of sample preparation and sealing conditions}

In order to be able to relate elastic modulus measurements (through EMM-ARM and CC) of NHL mortars with density, flexural and compressive strength tests, and open porosity, the latter were performed on prismatic specimens prepared and cured according to standard procedures (compacted and unsealed) and according to the ones adopted for EMM-ARM (vibrated and sealed). Also, specimens compacted and sealed were tested to analyze better the influence of each preparation method. The following sub-sections describe the main findings in such concern.

\subsubsection{Flexural and compressive strength tests}

Flexural and compressive strength were assessed at 2, 4 and 7 days of age on the three mortar mixes with different preparation methods: standard (compacted with 25 strokes of the tamper and unsealed), vibrated and sealed, and compacted and sealed. In Fig. 7, the results of the mixes prepared/cured with standard procedures (M0.8S, M0.9S and M1.1S), are plotted for the flexural strength (a) and the compressive strength (b). Each point represents the mean value of three specimens tested for the flexural strength and the one of the six resulting halves in the case of the compression strength. The error bars are the corresponding standard deviations. The results follow the expected path: mortars with lower water/lime ratios present higher flexural and compressive strengths. The flexural strengths of M0.8S and M0.9S are very similar to each other, in coherence with previous observations for the same mixes that had been studied at the age of 56 days [18].

Furthermore, the variability of results between mortars of different batches was tested for compression strength of the reference mortar, M0.9S: it was found to be less than $5 \%$ at day 7 , implying that the results present good repeatability. Standard deviations of results, as shown in Fig. 7, are also within acceptable 


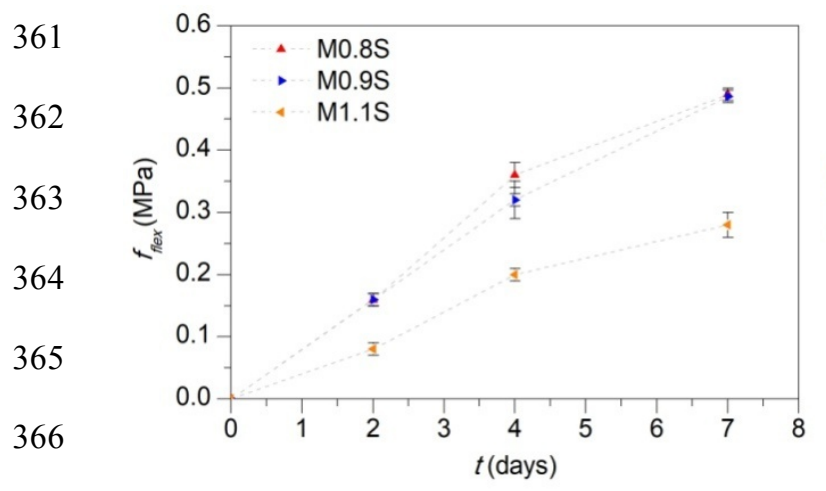

367 368 369

a)

ranges.

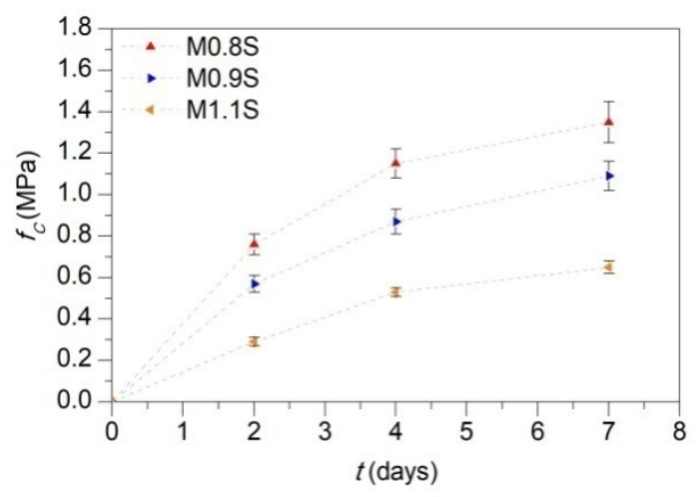

b)

Figure 7: Evolution of: a) flexural, b) compressive strengths with time.

In addition, Table 5 shows a comparison between results of different preparation methods (values in brackets refer to the standard deviation). Here, $\left(f_{s}-f_{v}\right) / f_{s}(\%)$ and $\left(f_{s}-f_{c}\right) / f_{s}(\%)$ refer to the relative difference of the strength of vibrated and sealed (V) and compacted and sealed (C) specimens, respectively, in relation to the corresponding standard (S) beams. In general, mortars that are sealed provide lower flexural and compressive strengths compared to the standard ones. For example, for the reference mortar, M0.9 (at day 7), the flexural strength is $49 \%$ smaller for both mortars that are vibrated and sealed (V) and compacted and sealed (C), as compared to the standard situation (S). Furthermore, in comparison to the standard situation (S), the compressive strength is approximately $21 \%$ smaller in the mortars that are vibrated and sealed (V) and $29 \%$ in the ones that are compacted and sealed (C). This could be, at least partially, due to the fact that the sealed specimens (kept in the climatic chamber inside

Table 5: Influence of the compacting method and curing conditions on the mechanical properties and comparison with the corresponding standard mortars at day 7 .

\begin{tabular}{|c|c|c|c|c|c|c|}
\hline & \multicolumn{3}{|c|}{ Flexural strength $(\mathrm{MPa})$} & \multicolumn{3}{|c|}{ Compressive strength (MPa) } \\
\hline & M0.8 & M0.9 & M1.1 & M0.8 & M0.9 & M1.1 \\
\hline \multirow{2}{*}{ S } & 0.49 & 0.49 & 0.28 & 1.35 & 1.09 & 0.65 \\
\hline & $(0.01)$ & $(0.01)$ & $(0.02)$ & $(0.10)$ & $(0.07)$ & $(0.03)$ \\
\hline \multirow{2}{*}{$\mathrm{V}$} & 0.28 & 0.25 & 0.14 & 1.06 & 0.86 & 0.47 \\
\hline & $(0.06)$ & $(0.01)$ & $(0.01)$ & $(0.04)$ & $(0.03)$ & $(0.01)$ \\
\hline \multirow{4}{*}{$\mathrm{C}$} & 0.28 & 0.25 & 0.14 & 1.07 & 0.77 & 0.48 \\
\hline & $(0.01)$ & $(0.02)$ & $(0.01)$ & $(0.06)$ & $(0.06)$ & $(0.02)$ \\
\hline & \multicolumn{3}{|c|}{ Decrease on flexural strength $(\%)$} & \multicolumn{3}{|c|}{$\begin{array}{l}\text { Decrease on compressive strength } \\
(\%)\end{array}$} \\
\hline & M0.8 & M0.9 & M1.1 & M0.8 & M0.9 & M1.1 \\
\hline$\frac{f_{s}-f_{v}}{f_{s}}(\%)$ & 43 & 49 & 50 & 22 & 21 & 27 \\
\hline$\frac{f_{s}-f_{c}}{f_{s}}(\%)$ & 44 & 49 & 49 & 21 & 29 & 26 \\
\hline
\end{tabular}


two plastic bags) were still wet during testing as they could not be air dried in the climatic chamber as the unsealed ones (just kept in the climatic chamber in contact with the air). A similar phenomenon was observed in [40], where brick masonry prisms and its components (bricks and three types of cement mortars with different cement to sand ratios) were air cured at $30^{\circ} \mathrm{C}$ and $\mathrm{RH} 90 \%$ for 28 days. After this period, the specimens were divided into three groups and stored in oven-dry state (oven drying at $105^{\circ} \mathrm{C}$ ), air dry (at $30^{\circ} \mathrm{C}$ and $\mathrm{RH} 90 \%$ ) and wet state (water immersion) for 24 hours. Then, they were tested for compressive strength, bond test and direct shear test. The results showed that the compressive strength of the weakest cement mortar could be $15.9 \%$ less for wet specimens in comparison to the air dried specimens (at $30^{\circ} \mathrm{C}$ and $\mathrm{RH} 90 \%$ ). Popovics [41] related this variation between wet and air cured specimens to the increase of the internal pressure in wet conditions due to a higher amount of water present in pores. Under this situation, the chance of cracking in a mortar with lesser external load increases and therefore the compressive strength is reduced. More detailed information on this phenomenon can be seen in [40].

Finally, it is worth remarking that the results of mortars that are vibrated and sealed and compacted and sealed are quite similar, meaning that the compaction method may not have much influence on the mechanical strength of NHL mortars at early stages.

In addition, the results of flexural and compressive strength of the mortars with the three different preparation methods were normalized with respect to their values at day $7\left(f_{f l e x} / f_{f l e x D}\right.$ and $f_{c} / f_{c D 7}$, respectively). Then, non-dimensional evolution curves of flexural (Fig. 8 (a)) and compressive (Fig. 8 (b)) strengths with time were obtained as shown for the standard (S) mortar, as the kinetics of evolution was rather similar in all cases. Equations 6 and 7 and Table 6 show the corresponding non-dimensional

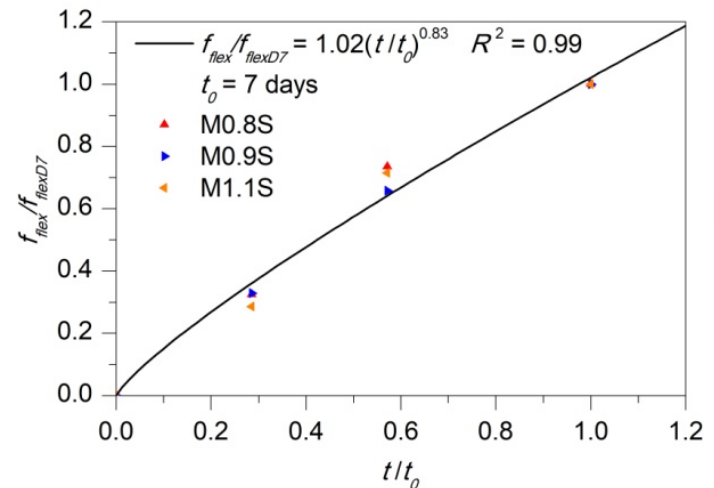

a)

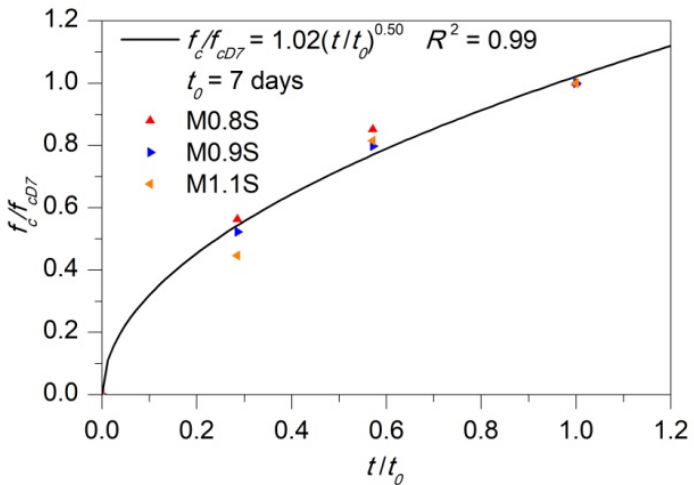

b)

Figure 8: Non-dimensional evolution curves of a) flexural and b) compressive strengths with time for the standard (S) mortar. 
$413 \frac{f_{\text {flex }}}{f_{\text {flex }_{D 7}}}=p\left(\frac{t}{t_{0}}\right)^{q}$

$414 \quad \frac{f_{C}}{f_{c_{D 7}}}=r\left(\frac{t}{t_{0}}\right)^{u}$

415

416 Where $t_{0}$ are 7 days.

Table 6:Coefficients of equations 6 and 7.

\begin{tabular}{llllll}
\hline & & $\mathrm{S}$ & $\mathrm{V}$ & $\mathrm{C}$ & $\begin{array}{l}\text { Mean } \\
(\mathrm{CoV})\end{array}$ \\
\hline Flexural & $p$ & 1.02 & 1.01 & 1.00 & $1.01(1 \%)$ \\
strength & $q$ & 0.83 & 0.71 & 0.80 & $0.78(8 \%)$ \\
\hline Compressive & $r$ & 1.02 & 1.02 & 1.00 & $1.01(1 \%)$ \\
strength & $u$ & 0.50 & 0.54 & 0.52 & $0.52(4 \%)$ \\
\hline
\end{tabular}

418

419 tendencies for the three mortars with the three preparation methods (standards, S; vibrated and sealed, V;

420 and compacted and sealed, C). These equations can be useful to obtain the flexural and compressive

421 strengths of different NHL mortars at early ages just by knowing their corresponding values at day 7 ,

422 which can also be useful for numerical models with NHL mortars at early ages.

423 To assess the impact of the three different variables used, namely - preparation method (S, V or C),

424 the time of testing (2, 4 or 7 curing days) and the water/lime ratio (0.8, 0.9 or 1.1$)$, a three-way ANOVA

425 test was performed, using the software Matlab R2016 [42]. In Table 7, $p$ values lower than 0.05 indicate

426 significance of the corresponding factor. Observing the results, it may be concluded that both the

427 preparation method as well as the water/lime ratio do not have a significant effect on the non-dimensional

428 Table 7: Results of a three-way ANOVA of the influence of three factors on the non-dimensional flexural and compressive strengths.

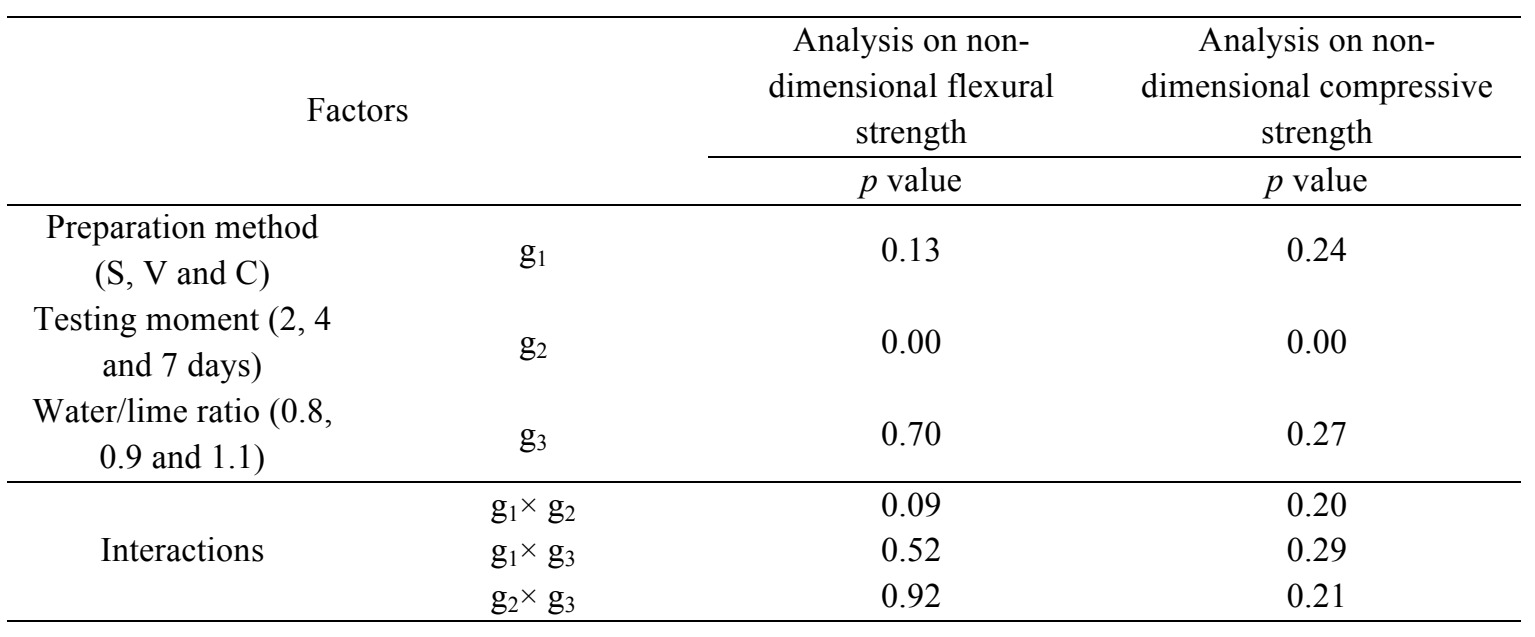


431 evolution curves of flexural and compressive strength ( $p$ value $>0.05)$, while, the time of testing does

432 have an influence ( $p$ value $<0.05$ ). In addition, from Table 7, it may also be observed that the interaction

433 of the three factors does not have any statistical significance.

434 We have proposed the use of a single value for each of the coefficients $p, q, r$ and $u$. This is because 435 the percentages of variation from the mean values were found to be low. Furthermore, from the results of 436 ANOVA, it was found that the method of sample preparation did not have a statistically significant 437 impact on the non-dimensional evolution of compressive and flexural. This implies that the two general 438 equations with mean coefficients could be used to describe the non-dimensional evolution of flexural and 439 compressive strengths up to 7 days of curing age, independent of the preparation method and the 440 water/lime ratio.

\subsubsection{UPV}

Before performing flexural and compressive strengths, discrete measurements of UPV were taken in the transverse direction of samples at day 2, 4 and 7. In this case, standard mortars (M0.8S, M0.9S and M1.1S) were compared with mortars that are vibrated and sealed (M0.8V, M0.9V and M1.1V) (see Table 8, where the values in brackets indicate the standard deviation). Results from Table 4 show a similar trend as the one observed for mechanical properties: mortars with lower water/lime ratios present higher velocities than the ones with higher water/lime ratios. For example, pulse velocity measured on average was $1750 \mathrm{~m} / \mathrm{s}, 1530 \mathrm{~m} / \mathrm{s}$ and $1300 \mathrm{~m} / \mathrm{s}$ for M0.8S, M0.9S and M1.1S, respectively, at day 7 . Variability of results among mortars of different batches was also checked for the reference mortar, M0.9S, and found to be less than $5 \%$ at day 7 , confirming good repeatability of the tests. On the other hand, comparison of results between vibrated and sealed counterparts of the standard mortar shows that the latter presents higher values of transverse velocity compared to the standard ones. For example, it was $2070 \mathrm{~m} / \mathrm{s}$ in the reference mortar vibrated and sealed, M0.9V, while for the standard reference mortar, M0.9S, it was $1530 \mathrm{~m} / \mathrm{s}$. It is noted that this trend is opposite to the one described for compressive/flexural strength (and even elastic-modulus) described in the previous sections, where the " $\mathrm{S}$ " mixes were systematically presenting higher values for mechanical properties compared to "V" mixes. This fact can be interpreted by the influence of water present in the porous network of the specimens during testing, which can play a role in the measured UPV. According to Lencis et al. [43] and Lafhaj et al. [44], UPV measurements increase with the material's degree of saturation. For example, for concrete, UPV can be $19 \%$ higher in 

sealed (V) mortars.

\begin{tabular}{lllll}
\hline \multicolumn{6}{c}{ Transverse wave velocity $(\mathrm{m} / \mathrm{s})$} \\
\hline & Curing days & M0.8 & M0.9 & M1.1 \\
\hline \multirow{3}{*}{$\mathrm{S}$} & 2 & $1430(40)$ & $1230(80)$ & - \\
& 4 & $1530(20)$ & $1300(20)$ & $1030(40)$ \\
& 7 & $1750(50)$ & $1530(10)$ & $1300(20)$ \\
\hline & 2 & $1790(20)$ & $1800(30)$ & $1500(60)$ \\
$\mathrm{V}$ & 4 & $1970(60)$ & $2020(60)$ & $1550(200)$ \\
& 7 & $2110(50)$ & $2070(20)$ & $1630(80)$ \\
\hline
\end{tabular}

fully saturated specimens in comparison to the completely dry ones [43]. Also Bungey [45] showed that UPV in wet concrete specimens was higher than in the corresponding dry ones. Considering this, it is reasonable that UPV values may be higher in the sealed specimens as they were still wet in the moment of testing, in comparison to the standard ones that were air dried in the climatic chamber.

\subsubsection{Density and open porosity}

Relationships were also established among the physical properties measured on the NHL mortars, such as wave propagation velocity from UPV, density and open porosity. Density was measured for all mortars at day 2, 4 and 7 just before performing flexural and compressive strengths (the weight of each sample was divided by their corresponding volume). In general, the results of density follow the same trend as that of mechanical properties and UPV (see Table 9 where the values in brackets are the standard deviation): mortars with lower water/lime ratios present higher values of density. For example, it is $2.08 \mathrm{~g} / \mathrm{cm}^{3}, 2.03 \mathrm{~g} / \mathrm{cm}^{3}$ and $1.94 \mathrm{~g} / \mathrm{cm}^{3}$, respectively for standard mortars M0.8S, M0.9S and M1.1S. On the other hand, for all mortar compositions, density tends to decrease with time in the first seven curing days, probably, due to the evaporation of water present inside the mortars. For instance, it is $2.21 \mathrm{~g} / \mathrm{cm}^{3}$ at day 2 and $2.03 \mathrm{~g} / \mathrm{cm}^{3}$ at day 7 for reference mortar M0.9S. Furthermore, comparing mortars that are sealed with the standard ones, it is observed that the former have higher values of density as their water content is higher due to the sealed conditions. For example it changed from $2.24 \mathrm{~g} / \mathrm{cm}^{3}$ to $2.03 \mathrm{~g} / \mathrm{cm}^{3}$ when comparing M0.9V with M0.9S.

As for open porosity, standard mortars were compared with the vibrated and sealed ones at day 7 , see Table 10 (again values in brackets are standard deviation). In general, as water/lime ratio increases, 

and compacted and sealed (C) mortars.

\begin{tabular}{lllll}
\hline & Curing days & $\mathrm{M} 0.8\left(\mathrm{~g} / \mathrm{cm}^{3}\right)$ & $\mathrm{M} 0.9\left(\mathrm{~g} / \mathrm{cm}^{3}\right)$ & $\mathrm{M} 1.1\left(\mathrm{~g} / \mathrm{cm}^{3}\right)$ \\
\hline \multirow{6}{*}{$\mathrm{S}$} & 2 & $2.25(0.01)$ & $2.21(0.01)$ & $2.17(0.01)$ \\
& 4 & $2.18(0.02)$ & $2.12(0.01)$ & $2.06(0.01)$ \\
& 7 & $2.09(0.01)$ & $2.03(0.01)$ & $1.94(0.01)$ \\
\hline \multirow{3}{*}{$\mathrm{V}$} & 2 & $2.25(0.01)$ & $2.25(0.01)$ & $2.20(0.04)$ \\
& 4 & $2.24(0.01)$ & $2.25(0.01)$ & $2.18(0.02)$ \\
& 7 & $2.23(0.01)$ & $2.24(0.01)$ & $2.17(0.04)$ \\
\hline \multirow{3}{*}{$\mathrm{C}$} & 2 & $2.31(0.01)$ & $2.28(0.01)$ & $2.20(0.01)$ \\
& 4 & $2.29(0.01)$ & $2.28(0.001)$ & $2.20(0.01)$ \\
& 7 & $2.27(0.01)$ & $2.27(0.001)$ & $2.20(0.01)$ \\
\hline
\end{tabular}

486

Note: values in brackets are standard deviations.

488 porosity also does, measuring $26.1 \%, 27.2 \%$ and $29.9 \%$, respectively for mortars M0.8S, M0.9S and

489 M1.1S. Comparing both preparation methods, it was checked that open porosity was slightly higher for

490 the mortars that are vibrated and sealed in comparison with the standard ones, but in fact this difference is

491 very low and in most cases it is within the margin of error.

492

Table 10: Results of open porosity at day 7 for the standard (S) and vibrated and sealed (V) mortars.

\begin{tabular}{lllll}
\hline & Curing days & M0.8 (\%) & M0.9 (\%) & M1.1 (\%) \\
\hline $\mathrm{S}$ & 7 & $26.1(0.3)$ & $27.2(0.2)$ & $29.9(0.4)$ \\
\hline $\mathrm{V}$ & 7 & $26.5(0.2)$ & $28.0(0.3)$ & $30.9(0.2)$ \\
\hline
\end{tabular}

Note: values in brackets are standard deviations.

Figure 9 shows some of these tendencies in relation to results of UPV for the standard mortars

(M0.8S, M0.9S and M1.1S) at day 7. In general, it can be observed that as open porosity increases, increases and therefore open porosity also increases with a consequent decrease of the wave propagation

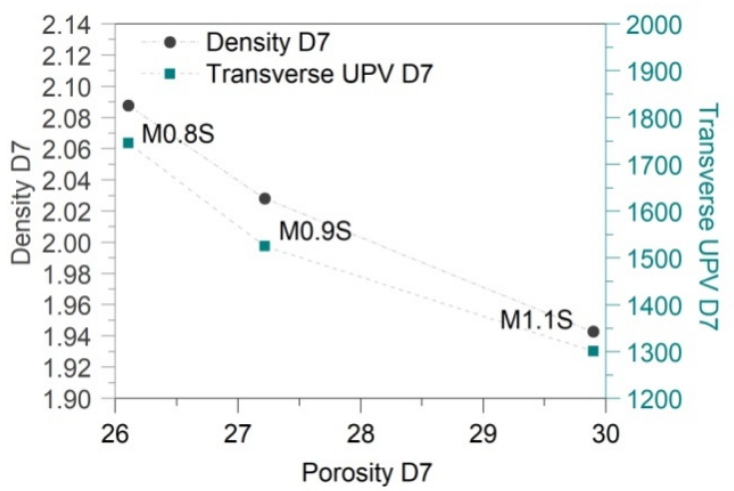

Figure 9: Relationship between open porosity, density and UPV at day 7 for M0.9S. 
509 velocity. Similar trends of pulse velocity decreasing with porosity, were also observed by Lafhaj et al.

510 [44] for cement mortars.

\section{$511 \quad 3.3$ Thermogravimetric analyses}

512 The material was also characterized by means of free portlandite content through thermogravimetric 513 analysis (TGA). For this purpose, tests were performed at day 0, 2, 4 and 7 on the corresponding lime 514 paste, P0.9, of the reference mortar. The samples were sealed until the moment of testing in order to study

515 the evolution of hydration by measurement of free portlandite content and to avoid carbonation reaction.

516 Figure 10 shows the relation between free portlandite content of P0.9 and the compressive strength of 517 mortar M0.9V at the same curing age. It can be observed that portlandite content increases as a function 518 of the compressive strength. A similar trend was also observed by Boualleg et al.[46] for cement pastes 519 and mortars. They obtained a linear fitting for different cement samples while we obtain a similar linear 520 adjustment for the same sample at different curing days. Lanas et al.[3] also studied the evolution of free 521 portlandite content on NHL mortars and they observed that it increased up to 28 or 91 days depending on 522 the lime/aggregate ratio. In Fig. 10, it may be remarked that the presence of free portlandite at day 0 , is typical of the nature of raw material itself. For example, in the work by Arizzi et al. [47], the raw NHL

5243.5 presented a content of portlandite between $40 \%$ and $50 \%$. This amount is coherent with results of 525 XRD of the NHL 3.5 of the present study (Table 1 and Fig. 1), where a range between $40 \%$ and $45 \%$ of 526 portlandite is obtained.

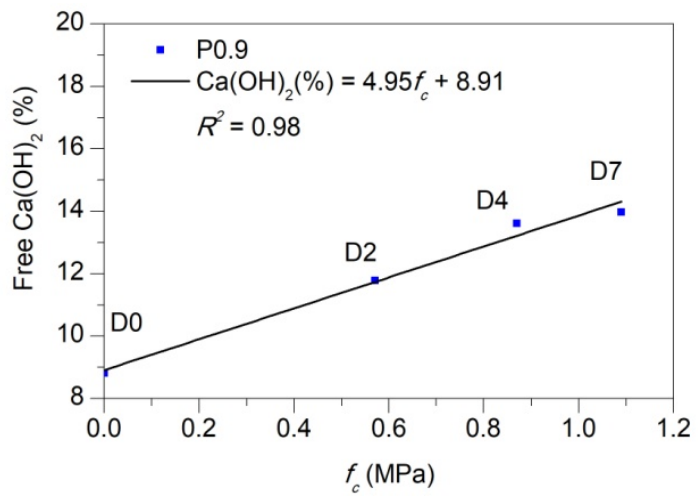

Figure 10: Free portlandite content as a function of compressive strength on the reference sealed paste samples. 


\section{CONCLUSIONS}

In this research, properties of three NHL type 3.5 mortars with different water/lime ratios and same lime/aggregate ratio are studied at early ages, such as density, flexural and compressive strengths, stiffness evolution through EMM-ARM and CC, and the evolution of free portlandite content with time. An exhaustive physical and mechanical characterization was performed on the material under different fabrication and curing methods: standard procedures (compacting and unsealing), vibration and sealing, and compacting and sealing. The results show good repeatability in the tests, especially in EMM-ARM, flexural and compressive strength tests. The following main conclusions can be extracted from this research:

(1) The EMM-ARM method has shown feasible potential of application to the study of NHL mortars at early ages $(<3-7$ days $)$, with very good repeatability and comparability with results obtained from $\mathrm{CC}$ testing (with both standard compaction/curing and non-standard curing involving vibration and sealing). The initial dormant period was well captured, as well as the entire kinetics of stiffness increase, which was clearly different amongst the three studied mortars. As time passes, the standard curing condition allows specimens to harden further, the results attained by EMM-ARM (in sealed conditions) start to deviate from the CC results with standard curing (less stiffness assessed by EMM-ARM). Therefore, if EMM-ARM is to be applied for longer durations, more than a mere couple of days, adaptations to the test setup are necessary, so as to allow carbonation. These adaptations will bring new challenges due to mass variations of the specimen during testing, which will need to be monitored, so as to provide adequate estimates of elastic-modulus (obtained through the dynamic equation of motion that requires the mass of the specimen which is no longer constant).

(2) Flexural and compressive strengths behave as expected: mortars with lower water/lime ratios present higher strengths. Comparing standard- i.e., air cured specimens (S) with the ones that are sealed ( $\mathrm{V}$ and $\mathrm{C}$ ), it is observed that the latter have lower strength. These results were unexpected since the sealed specimens were subjected to more humid moisture curing conditions and therefore higher degrees of hydration. One possible explanation for this may be that the sealed specimens were more wet at the moment of testing compared to the unsealed specimens (subjected to air curing) and therefore exhibited lower values of mechanical strength as 
discussed by other researchers $[40,41]$. Further research would be needed to study the effect of wetting conditions on NHL mortars.

(3) Furthermore, the evolution tendencies of normalized flexural and compressive strength with respect to their corresponding values at day 7 were obtained. These formulas could be useful for numerical models with NHL mortars at early ages. It must be noted though, that these evolution

(4) Discrete measurements of UPV were also taken in the transverse direction of the prismatic (by volume) and employing limestone aggregates.

specimens just before performing flexural and compressive strength tests. The results showed that pulse velocity increased with lower water/lime ratios. Furthermore, velocity also increased in specimens that were more humid, such as the sealed ones. This is possibly related to longitudinal waves propagating faster through pores filled with water than through the ones filled with air [48]. Such tendencies appear to be similar to the ones found by Lencis et al. [43], Lafhaj et al. [44] and Bungey [45]. This caused the sealed specimens to exhibit higher UPV than the standard cured specimens, which is an opposing trend to the one found in other mechanical tested properties (strength and stiffness). A word of caution is thereby issued on potentially misleading observations that might be taken when comparing UPV test results of specimens cured under different conditions.

(5) Density follows the same trend as flexural and compressive strength and UPV: it is higher for mortars with lower water/lime ratios. Comparing specimens that are sealed with the standard ones, it was observed that the former has higher values of density as they are more humid.

(6) Open porosity was measured at day 7 and, as expected it increases with higher water/lime ratios. In general, it was observed that density and pulse velocity decreased as open porosity increased.

(7) Finally, the evolution of free portlandite content was measured in the reference lime paste at days $0,2,4$ and 7 . It was related to the compressive strength of the mortar with the same composition at corresponding ages. This relation was adjusted with a linear fitting up to day 7 . Other authors [3] also observed that free portlandite content increased up to day 28 or 91 depending on the lime/aggregate ratio of NHL mortars. 
The authors wish to thank the funding provided by the Portuguese Foundation for Science and Technology (FCT) to the Research Projects and PTDC/ECM-EST/1056/2014 (POCI-01-0145-FEDER016841), as well to the Research Unit ISISE (POCI-01-0145-FEDER-007633), also from the Ministerio de Economía y Competitividad, Spain, under grant BIA2015-68678-C2-1-R. Lucía Garijo acknowledges financial support from the scholarship FPU014/05186 awarded by the Ministerio de Educación, Cultura y Deporte, Spain, from the scholarship 2016/11635 given by Universidad de Castilla-La Mancha (UCLM) to do a research stay in another institution and from the research project RTC-2017-6736-3 awarded by the Ministerio de Ciencia, Innovación y Universidades, Spain. Advice on the fabrication of NHL mortars provided by Prof. Pere Roca from Universidad Politécnica de Cataluña are also much appreciated. We also thank the research group of Prof. Anselmo Acosta in UCLM for their help on the chemical and mineralogical analyses of the raw NHL and the company Iesmat, Instrumentación especifica de materiales, for the laser particle size distribution of the raw NHL.

\section{8}

\section{REFERENCES}

[1] Kalagri A, Karatasios I, Kilikoglou V. The effect of aggregate size and type of binder on microstructure and mechanical properties of NHL mortars. Construction and Building Materials. 2014;53:467-74.

[2] Chan R, Bindiganavile V. Toughness of fibre reinforced hydraulic lime mortar. Part-1: Quasi-static response. Materials and Structures. 2010;43(10):1435-44.

[3] Lanas J, Bernal JLP, Bello MA, Galindo JIA. Mechanical properties of natural hydraulic lime-based mortars. Cement and Concrete Research. 2004;34(12):2191-201.

[4] Arandigoyen M, Alvarez JI. Pore structure and mechanical properties of cement-lime mortars. Cement and Concrete Research. 2007;37(5):767-75.

[5] Azenha M, Magalhaes F, Faria R, Cunha A. Measurement of concrete E-modulus evolution since casting: A novel method based on ambient vibration. Cement and Concrete Research. 2010;40(7):1096105.

[6] Azenha M, Ramos LF, Aguilar R, Granja JL. Continuous monitoring of concrete E-modulus since casting based on modal identification: A case study for in situ application. Cement \& Concrete Composites. 2012;34(7):881-90.

[7] Azenha M, Faria R, Magalhaes F, Ramos L, Cunha A. Measurement of the E-modulus of cement pastes and mortars since casting, using a vibration based technique. Materials and Structures. 2012;45(12):81-92.

[8] Azenha M. Numerical Simulation of The Structural Behaviour of Concrete Since its Early Ages. [PhD Thesis]: Faculty of Engineering of the University of Porto; 2009.

[9] Azenha M, Magalhães F, Ramos L. Method based in ambient vibrations for quantifying the evolution of E-modulus of hardening materials. Portugal patent application 104413. 2009.

[10] BS EN 1015-11. Methods of test for mortar for masonry - Part 11: Determination of flexural and compressive strength of hardened mortar: BSI; 1999/A1:2006. p. 12.

[11] BS EN 459-1. Building lime - Part 1: Definitions, specifications and conformity criteria. Brussels, Belgium: BSI; 2015. p. 52.

[12] BS EN 1015-1. Methods of test for mortar for masonry - Part 1: Determination of particle size distribution (by sieve analysis): BSI; 1998/A1:2006. p. 8. 
[13] BS EN 1097-6. Test for mechanical and physical properties of aggregates - Part 6: Determination of particle density and water absorption: BSI; 2013. p. 54.

[14] BS EN 1097-3. Test for mechanical and physical properties of aggregates - Part 3: Determination of loose bulk density and voids: BSI; 1998. p. 10.

[15] BS EN 1015-3. Methods of test for mortar for masonry - Part 3: Determination of consistence of fresh mortar (by flow table): BSI; 1999/A2:2006. p. 10.

[16] BS EN 1015-6. Methods of test for mortar for masonry - Part 6: Determination of bulk density of fresh mortar: BSI; 1998/A1:2006. p. 8.

[17] BS EN 1015-2. Methods of test for mortar for masonry - Part 2: Bulk sampling of mortars and preparation of test mortars: BSI; 1998/A1:2006. p. 8.

[18] Garijo L, Zhang XX, Ruiz G, Ortega JJ, Wu Z. The effects of dosage and production process on the mechanical and physical properties of natural hydraulic lime mortars. Construction and Building Materials 2018;169:325-34.

[19] Grilo J, Silva AS, Faria P, Gameiro A, Veiga R, Velosa A. Mechanical and mineralogical properties of natural hydraulic lime-metakaolin mortars in different curing conditions. Construction and Building Materials. 2014;51:287-94.

[20] Lanas J, Sirera R, Alvarez JI. Study of the mechanical behavior of masonry repair lime-based mortars cured and exposed under different conditions. Cement and Concrete Research. 2006;36(5):96170.

[21] Maia L, Azenha M, Faria R, Figueiras J. Influence of the cementitious paste composition on the Emodulus and heat of hydration evolutions. Cement and Concrete Research. 2011;41(8):799-807.

[22] Maia L, Azenha M, Geiker M, Figueiras J. E-modulus evolution and its relation to solids formation of pastes from commercial cements. Cement and Concrete Research. 2012;42(7):928-36.

[23] Granja JL, Azenha M, de Sousa C, Ferreira C. Comparison Between Different Experimental Techniques for Stiffness Monitoring of Cement Pastes. Journal of Advanced Concrete Technology. 2014;12(2):46-61.

[24] Granja J, Azenha M. Towards a robust and versatile method for monitoring E-modulus of concrete since casting: Enhancements and extensions of EMM-ARM. Strain. 2017;53(4).

[25] Ramesh M, Azenha M, Lourenço PB. Mechanical properties of lime-cement masonry mortars in their early ages. Materials and Structures. 2019;52(1).

[26] Granja J, Azenha M. Elastic Modulus Measurement through Ambient Response Method. User's Guide. University of Minho.

[27] Garijo L, Zhang XX, Ruiz G, Ortega JJ, Yu RC. Advanced mechanical characterization of NHL mortars and cohesive simulation of their failure behavior. Construction and Building Materials. 2017;153:569-77.

[28] ASTM. C403/C 403M-99. Standard Test Method for Time of Setting of Concrete Mixtures by Penetration Resistance. West Conshohocken, United States: ASTM; 1999.

[29] Meyers MA, Chawla KK. Mechanical Behavior of Materials. Second Edition. New York, USA: Cambridge University Press; 2008.

[30] UNE 83980. Concrete durability - Test methods - Determination of the water absorption, density and accessible porosity for water in concrete. Madrid: AENOR; 2014. p. 8.

[31] Montoya C, Lanas J, Arandigoyen M, Navarro I, Casado PJG, Alvarez JI. Study of ancient dolomitic mortars of the church of Santa Maria de Zamarce in Navarra (Spain): comparison with simulated standards. Thermochimica Acta. 2003;398(1-2):107-22.

[32] Parrott LJ, Killoh DC. Carbonation in a 36 year old, in-situ concrete. Cement and Concrete Research. 1989;19(4):649-56.

[33] Oliveira MA, Azenha M, Lourenco PB, Meneghini A, Guimaraes ET, Castro F, Soares D. Experimental analysis of the carbonation and humidity diffusion processes in aerial time mortar. Construction and Building Materials. 2017;148:38-48.

[34] Silva DA, Wenk HR, Monteiro PJM. Comparative investigation of mortars from Roman Colosseum and cistern. Thermochimica Acta. 2005;438(1-2):35-40.

[35] Scrivener K, Snellings R, Lothenbach B. A practical Guide to Microstructural Analysis of Cementitious Materials. In: Press C, editor.: Taylor \& Francis Group; 2016.

[36] Oliveira MA. A Multi-Physics Approach Applied to Masonry Structures with Non-Hydraulic Lime Mortars [PhD Thesis]. Guimaraes, Portugal: University of Minho; 2015.

[37] Lawrence RMH, Mays TJ, Walker P, D'Ayala D. Determination of carbonation profiles in nonhydraulic lime mortars using thermogravimetric analysis. Thermochimica Acta. 2006;444(2):179-89. 
694 [38] Cizer O. Competition between carbonation and hydration on the hardening of calcium hydroxide and 695 calcium silicate binders. [PhD Thesis]: Haverlee (Belgium): Katholieke Universiteit Leuven 2009.

696 [39] Granja JL. Continuous characterization of stiffness of cement-based materials: experimental analysis 697 and micro-mechanics modelling. [PhD Thesis]: Universidade do Minho, Escola de Engenharia; 2016.

698 [40] Sathiparan N, Rumeshkumar U. Effect of moisture condition on mechanical behavior of low strength 699 brick masonry. Journal of Building Engineering. 2018;17:23-31.

700 [41] Popovics S. Strength and Related Properties of Concrete: A Quantitative Aproach. Wiley, New 701 York1998.

702 [42] MathWorks, Moler C. Matlab. R2016b ed2016.

703 [43] Lencis U, Udris A, Korjakins A. Moisture Effect on the Ultrasonic Pulse Velocity in Concrete Cured [44] Lafhaj Z, Goueygou M, Djerbi A, Kaczmarek M. Correlation between porosity, permeability and ultrasonic parameters of mortar with variable water/cement ratio and water content. Cement and Concrete Research. 2006;36(4):625-33.

708 [45] Bungey JH. The validity of Ultrasonic Pulse Velocity testing of in-place concrete for strength. Ndt 709 International. 1980;13(6):296-300.

710 [46] Boualleg S, Bencheikh M, Belagraa L, Daoudi A, Chikouche MA. The Combined Effect of the Initial Cure and the Type of Cement on the Natural Carbonation, the Portlandite Content, and Nonevaporable Water in Blended Cement. Advances in Materials Science and Engineering. 2017:1-17.

713 [47] Arizzi A, Cultrone G, Brummer M, Viles H. A chemical, morphological and mineralogical study on 714 the interaction between hemp hurds and aerial and natural hydraulic lime particles: Implications for mortar manufacturing. Construction and Building Materials. 2015;75:375-84.

716 [48] Albert DG. A comparison between wave propagation in water-saturated and air-saturated porous 717 materials. Journal of Applied Physics. 1993;73(28):28-36. 